\title{
ADAPTIVITY OF THERMAL DIAGNOSTICS METHOD OF MECHANICAL TRANSMISSION ASSEMBLIES
}

\author{
Alexander Pastukhov ${ }^{1}$, Eugeny Timashov ${ }^{2}$, Igor Kravchenko ${ }^{3}$, Tatyana Parnikova ${ }^{1}$ \\ ${ }^{1}$ Belgorod State Agricultural University named after V. Gorin, Russia; ${ }^{2}$ Belgorod University of \\ Cooperation, Economics and Law, Russia; ${ }^{3}$ Russian Timiryazev State Agrarian University, Russia \\ pastukhov_ag@mail.ru, timachov@mail.ru,kravchenko-in71@yandex.ru, t-parnikova@mail.ru
}

\begin{abstract}
Determination of the real technical condition of mechanical transmissions is a key problem of diagnosing in the course of maintenance and repair of transport and technological machines in operation. The most reliable method of determining the technical condition of mechanical transmission assemblies taking into account the prospect of digitalization is thermal diagnostics based on the change in the intensity of infrared radiation of the heat source under normal conditions and under pre-failure condition. The aim of the research is practical testing of the method of thermal diagnostics based on the development of the analytical model of thermal stress and simulation of temperature loads by the method of finite-element analysis taking into account the resource bench tests on the example of the joints of drive lines. Research object - the cardan joint as per GOST R 52923-2008 (type 3 row IV, bearings 804707K4S10). The method of research includes: analytical study of cardan joint heat generation at three hierarchical levels of elementary joint "crosspin-bearing", crosspiece assembly and cardan joint assembly taking into account heat generation of adjacent parts and assemblies; simulation technique of stress-strain state taking into account thermal loading of parts on the basis of 3D-model of the joint using CAD-technology COMPAS 3D and CAE-technology APM FEM; comparative analysis of analytical and simulation technique results on the basis of data of resource bench tests on dynamics of radial play in the joint and temperature of bearing units at the level of extreme operational loading modes. As a result of the studies, the adequacy of the analytical mathematical model of the thermal stress of the cardan joint was confirmed, the method of simulation technique was verified and the operability of the complex method of thermal diagnostics for determining the real technical condition of mechanical transmission units was evaluated.
\end{abstract}

Keywords: temperature, diagnostics, transmission, model, simulation, test.

\section{Introduction}

The development and implementation of efficient technologies for ensuring the operational condition of transport and technological machines (TTM) is a pressing task for agricultural engineering and production. Technical diagnostics is an integral and essential part of the maintenance and repair system. The importance of technical diagnostics increases significantly for a reliable maintenance system (Reliability-centered maintenance - RCM). At present, effective technologies, methods and tools of technical diagnostics have been developed, ensuring continuous monitoring of transport and technological machine systems through integrated and telematic diagnostics systems. This approach allows to ensure efficient maintenance taking into account the impact of seasonality of agricultural works [1]. A common disadvantage of these technologies is their inability to control the technical condition of mechanical transmission elements, the operability of which limits the reliability of TTM.

Existing technologies and methods of diagnostics of mechanical transmissions, couplings and bearings are represented by variants of vibration diagnostics and measurement of shapes, dimensions and arrangement of part surfaces. Implementation of these methods is possible only during in-depth diagnostics operations during maintenance of the equipment and is connected with the need to disassemble the diagnosed node [2-4]. In this regard, the solution of problems of development of thermal diagnostics technologies and technical means of their implementation on the example of elements of mechanical transmissions seems to be very relevant.

Development and justification of technology for control of technical condition of mechanical transmission elements, on the example of drive lines, will allow to minimize costs for repair of equipment and costs from downtime, as well as to implement means of built-in diagnostics, thus providing technology of continuous diagnostics. In particular, the method of nondestructive thermometric testing of cardan bearing assemblies (CBA) based on own thermal radiation will solve the problem of continuous temperature monitoring and develop built-in diagnostic tools.

The aim of the research is practical testing of the method of thermal diagnostics based on the development of the analytical model of thermal stress and simulation technique of temperature loads 
by the method of finite-element analysis taking into account the resource bench tests on the example of the joints of the drive lines.

Research problems:

- Take into account the influence of structural, technological and operational factors on the temperature in the friction zone of the fuel element when developing the mathematical model;

- Establish the dependence of the diagnostic temperature on the temperature in the friction zone;

- Verify the mathematical model by bench tests;

- Establish the dependence of the diagnostic temperature on the radial play value taking into account the effect of heat emission of the coupled sources.

\section{Materials and methods}

Research object - the cardan joint as per GOST R 52923-2008 (type 3 row IV, bearings 804707K4S10). The research procedure includes: analytical analysis of the cardan joint heat generation at three hierarchical levels of elementary joint "crosspin-bearing" cross-piece assembled and cardan joint assembled taking into account heat generation of adjacent parts and assemblies.

The implementation of the technology of diagnosis of cardan joints based on the method of nondestructive thermometric testing is hindered by a number of factors. First, it is a significant number of structural, technological and operational factors [5-8]. Second, the friction zone of the CBA is below the outer surfaces suitable for temperature measurement. The value of the surface (diagnostic) temperature $\Theta_{D}$ will always be different from the value of the temperature in the friction zone $\Theta_{F}$, while this temperature characterizes the technical condition of the bearing assembly, and reaching its level of $200-250{ }^{\circ} \mathrm{C}$ indicates the onset of the limit condition. Thirdly, ambient temperature $\Theta_{0}$, heat release of adjacent heat-generating assemblies through the coefficient of $k$ and increment of temperature $\Theta_{\Delta}$ from increase in the play in bearings has an impact on the value of diagnostic temperature $\Theta_{D}$.

In order to establish the relationship between the diagnostic temperature and the temperature in the friction zone, it is necessary to develop an analytical model of the bearing assembly, taking into account the structural, technological and operational factors, as well as the value of the circular play $\Delta$ in the needle bearings of the cardan joint. The results of solving this model should be used as input for modeling temperature fields based on the 3D-model of the cardan joint using the CAD-technology COMPAS 3D and CAE-technology APM FEM.

In order to assess the reliability of the results of the study, as well as empirical assessment of the effect of the circular play, bench resource tests were carried out, at which temperature measurement in bearing assemblies was carried out by a resistance thermometer, including a digital meter CLR E7-13 and a measuring bridge made of thermistors located in bearing covers.

\section{Results and discussion}

The value of the diagnostic temperature of the subject of diagnostics taking into account the above facts is determined by the following polynomial [9].

$$
\Theta_{D}=\Theta_{0}+\Theta_{F} \cdot k+\Theta_{\Delta}
$$

where $\Theta_{D}$ - diagnostic temperature, ${ }^{\circ} \mathrm{C}$;

$\Theta_{0}-$ ambient temperature, ${ }^{\circ} \mathrm{C}$;

$\Theta_{F}$ - temperature in friction zone, ${ }^{\circ} \mathrm{C}$;

$k$ - coefficient of proportionality of finite-element model;

$\Theta_{\Delta}$ - temperature increment from radial play in bearing assemblies, ${ }^{\circ} \mathrm{C}$.

The development of an analytical mathematical model of temperature in the friction zone $\Theta_{F},{ }^{\circ} \mathrm{C}$, in relation to the joints of the drive lines is devoted to research [10], and the mathematical model obtained by us earlier takes into account the previously mentioned factors with the exception of the radial play in the CBA (2). 


$$
\Theta_{F}=\frac{\delta f M \omega \operatorname{tg} \gamma}{4 R I\left(\lambda \sqrt{\frac{\alpha(2 h+\pi r)}{\lambda \pi r h}+k^{\prime} \rho c 2.6 \frac{\sqrt{a}}{\lambda_{D}} \sqrt{\sin \gamma \omega r}}\right)},
$$

where $\delta$-coefficient of heat distribution between friction bodies;

$f$ - sliding friction coefficient;

$M$ - transferred torque, $\mathrm{Nm}$;

$\omega$ - angular speed, $\mathrm{rad} \cdot \mathrm{s}^{-1}$;

$\gamma$ - fracture angle in a joint, grad;

$R$ - average radius of spike rotation, $\mathrm{m}$;

$I$ - mechanical equivalent of warmth;

$\lambda$ - heat conductivity, $\mathrm{W} \cdot \mathrm{m}^{-1} \cdot{ }^{\circ} \mathrm{C}^{-1}$;

$\alpha$ - surface thermolysis coefficient, $\mathrm{W} \cdot \mathrm{m}^{-2} \cdot{ }^{\circ} \mathrm{C}^{-1}$;

$h$ - operating height of spike, m;

$r$ - crosspiece spike radius, $\mathrm{m}$;

$k^{\prime}$ - proportionality coefficient;

$\rho$ - firmness of material, $\mathrm{kg} \cdot \mathrm{m}^{-3}$;

$c$ - specific heat, $\mathrm{J} \cdot \mathrm{kg}^{-10} \cdot \mathrm{C}^{-1}$;

$a$ - thermal diffusivity coefficient, $\mathrm{m}^{2} \cdot \mathrm{s}^{-1}$;

$\lambda_{D}-$ wavelength of irregularities on friction surface, $\mathrm{m}$.

The calculated evaluation of the analytical model from the initial data for the study object - the cardan joint at torque of $2000 \mathrm{Nm}$, rotation speed of $104.7 \mathrm{~s}^{-1}$ and fracture angle of $12^{\circ}$ showed that the calculated theoretical temperature in the friction zone of the CBA is equal to $\Theta_{F}=118.7^{\circ} \mathrm{C}$.

To determine the proportionality factor $k$, a 3D-model was built in CAD KОМПАC 3D V18, and using the APM FEM module, the finite element analysis of temperature fields for a single CBA was carried out taking into account the system model at the I hierarchical level [9;10]. The resulting design temperature field map is shown in Fig. $1, a$ and the diagnostic temperature value is $\Theta_{D}=24.4^{\circ} \mathrm{C}$. Fig. 1,b shows the map of temperature fields for the cardan joint as a whole, taking into account the heat emission of the four CBA, which corresponds to the II level of the hierarchical system model. As a result of the simulation technique, the value of the diagnostic temperature is $\Theta_{D}=24.4^{\circ} \mathrm{C}$.

In order to obtain a complete picture of the temperature distribution, a 3D-model of the cardan joint installed in the test bench mechanism was constructed according to the type III hierarchical level of the system model, and an additional source of heat generation was the bearing assemblies of the closed power circuit, the load temperature of which, also determined according to model (2), was $35.8^{\circ} \mathrm{C}$. In Fig. 2 a map of the temperature fields for the cardan hinge installed in the bench outline is shown. Taking into account the conjugate elements, the diagnostic temperature was $\Theta_{D}=23.7^{\circ} \mathrm{C}$ at the friction zone temperature $\Theta_{F}=118.7^{\circ} \mathrm{C}$.

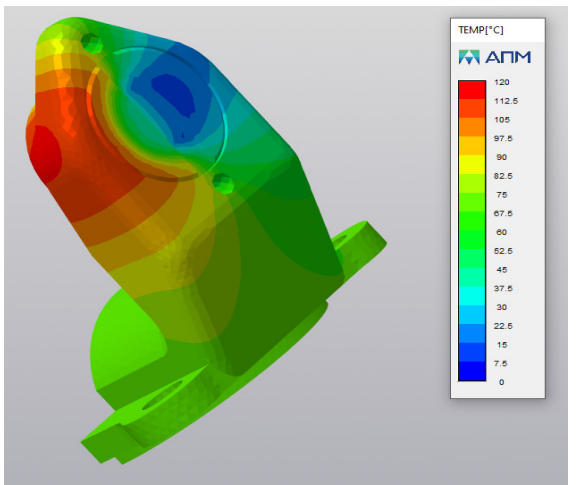

a) cardan bearing assembly

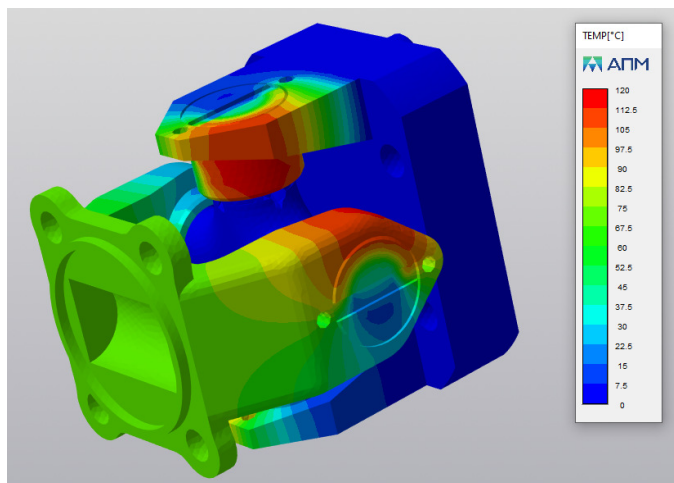

b) cardan joint as a whole

Fig. 1. Charts of temperature fields 


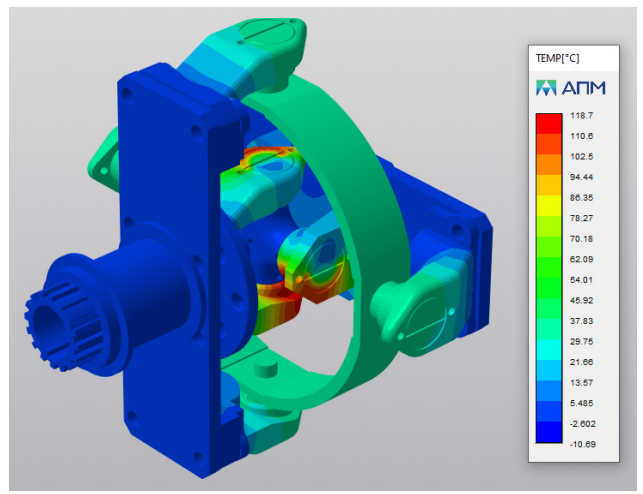

Fig. 2. Temperature field map of the joint in the stand

Figure 3 shows the graphical dependence of the diagnostic temperature on the temperature in the friction zone resulting from the simulation technique of temperature fields. The relationship is approximated by a linear function at $R^{2}=0.985$, by the equation of which the value of the proportionality coefficient is $k=0.202$.

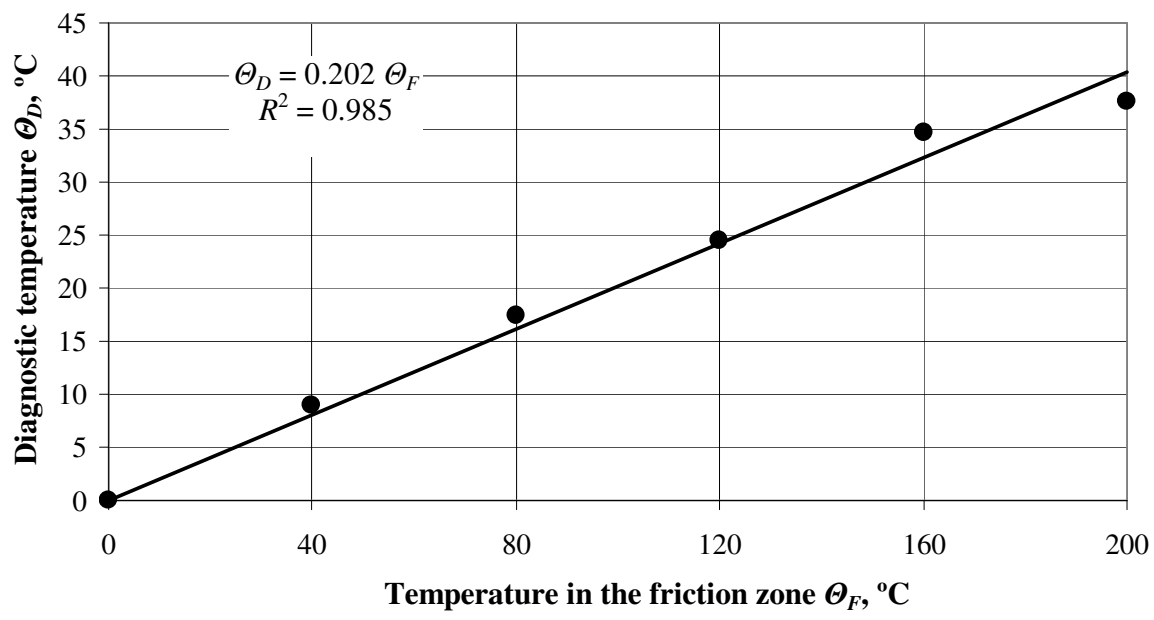

Fig. 3. Dependence of the diagnostic temperature $\Theta_{D}$ on the temperature in the friction zone $\Theta_{F}$

As a result of the bench tests, the average value of the diagnostic temperature $\Theta^{\prime}{ }_{D}=28.5^{\circ} \mathrm{C}$ was determined. Fig. 4 shows the empirical dependence of the CBA temperature on the radial play value obtained from the bench tests, which allows taking into account the effect of radial play in bearings according to the equation (3).

$$
\Theta_{\Delta}=\mu \Delta,
$$

where $\Delta$-radial play in the joint $\mathrm{CBA}, \mu \mathrm{m}$;

$\mu$ - proportionality coefficient (for this case $\mu=0.0614^{\circ} \mathrm{C} \cdot \mu \mathrm{m}^{-1}$ ).

Based on the results of the bench tests, simulation technique of temperature fields and taking into account dependencies (1)-(3), the diagnostic temperature for the cardan joint will be determined by the refined mathematical model of the type (4).

$$
\Theta_{D}=\Theta_{0}+\frac{0.202 \delta f M \omega \operatorname{tg} \gamma}{4 R I\left(\lambda \sqrt{\frac{\alpha(2 h+\pi r)}{\lambda \pi r h}}+k^{\prime} \rho c 2,6 \frac{\sqrt{a}}{\lambda_{D}} \sqrt{\sin \gamma \omega r}\right)}+0.0614 \Delta .
$$

With regard to the practical implementation of the thermometric diagnostics technology, it is necessary to solve the inverse problem: based on the value of the diagnostic measured temperature $\Theta_{D}$, calculate the value of the temperature in the friction zone $\Theta_{F}$ and compare it with the maximum permissible value $\Theta_{L}$. In this case, equation (4) is converted to (5). 


$$
\Theta_{F}=\frac{\Theta_{D}-\Theta_{0}-\mu \Delta}{k}<\Theta_{L} .
$$

Generalization of the results of the performed studies allows to develop the algorithm of application of the thermometric non-destructive test for joints of drive lines as a whole as for the unit. The offered scheme (Fig. 5) allows finding the coefficients $k$ and $\mu$ to be used in equation (5).

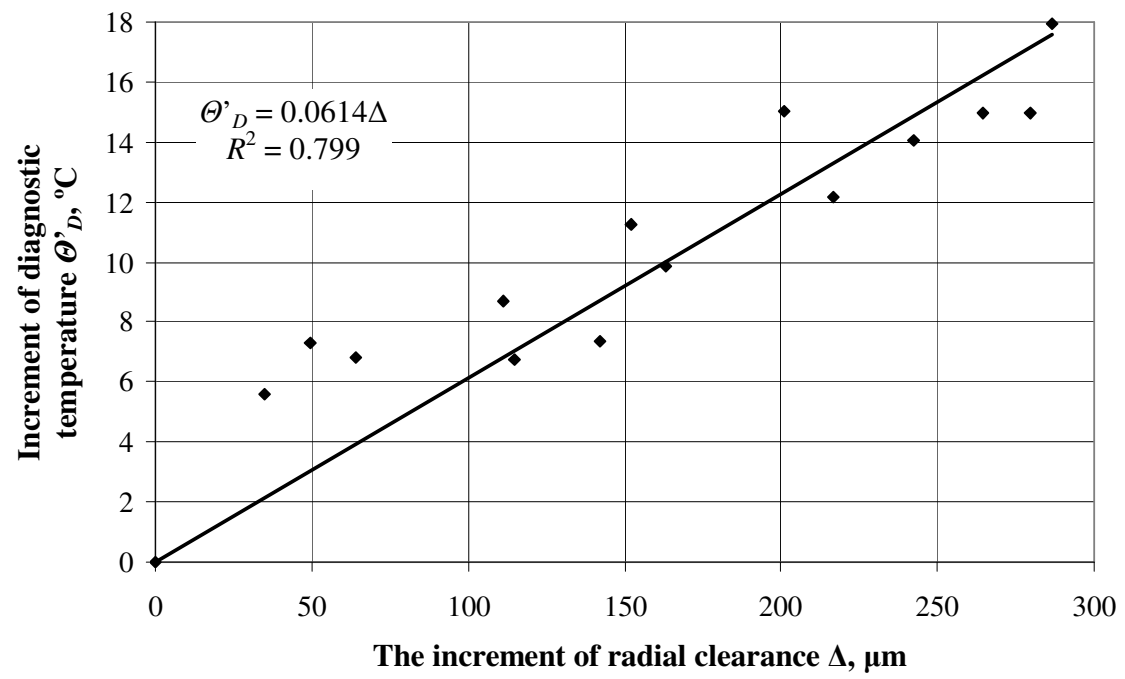

Fig. 4. Empirical dependence of temperature on radial play

Implementation of the algorithm involves collection and evaluation of design, process, operational parameters of the investigated unit, including $\Theta_{0}$ and $\Delta$. Calculation by the mathematical model determines temperature in the friction zone $\Theta_{F}$, and the finite element analysis of the temperature fields determines the diagnostic temperature $\Theta_{D}$ and the proportionality factor $k$. As a result of the bench tests, the diagnostic temperature $\Theta^{\prime}{ }_{D}$ and the proportionality coefficient $\mu$ are determined. The correctness of the mathematical model is checked by the convergence of theoretical and empirical values of the diagnostic temperature, after that the obtained coefficients are used in equation (5) for thermometric control of mechanical transmission assemblies.

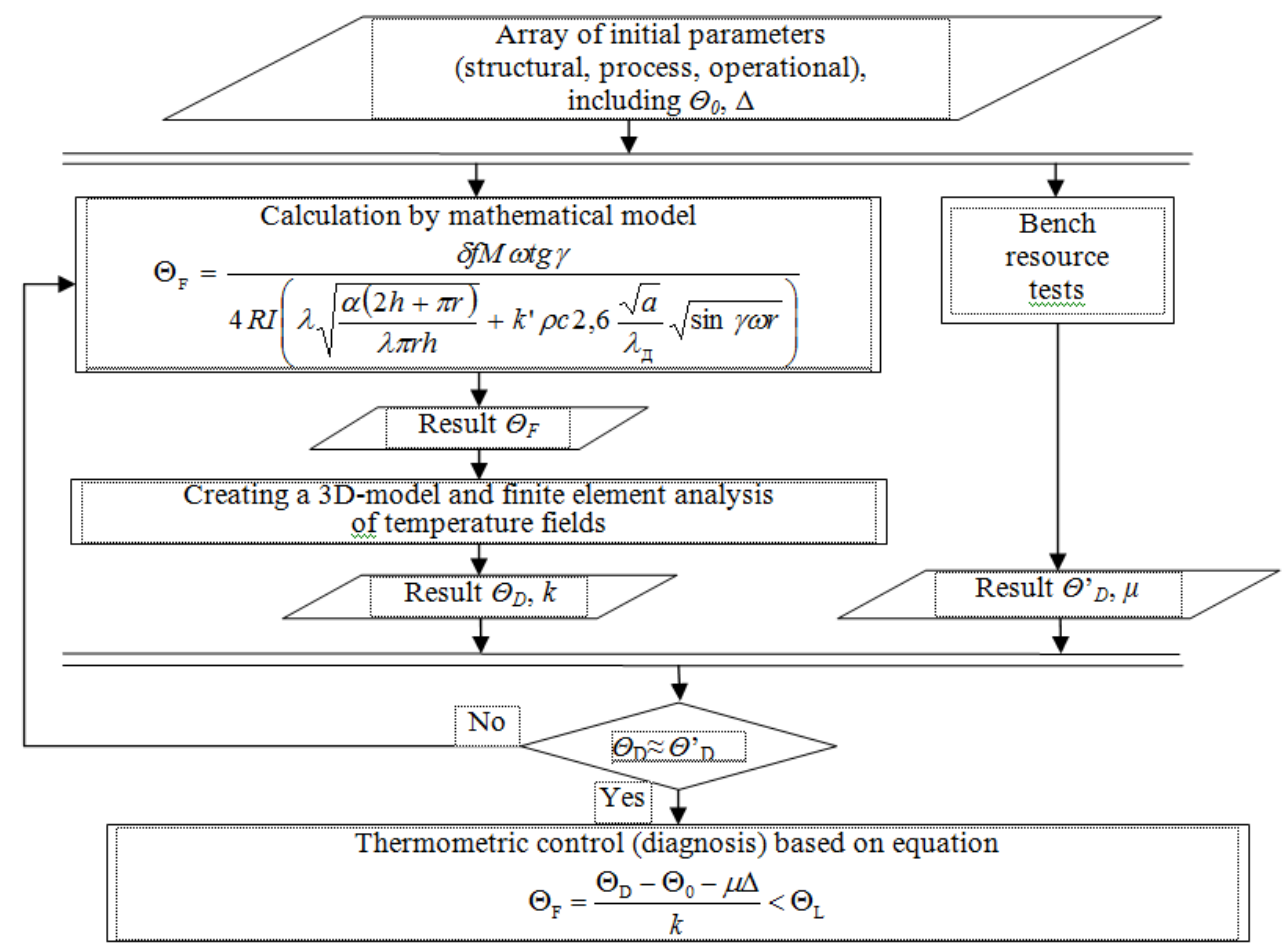

Fig. 5. Algorithm for implementation of thermometric nondestructive testing of drive line joints 
To compare the theoretical and experimental results, the mean value of the diagnostic temperature obtained by simulating $23.7^{\circ} \mathrm{C}$ should be corrected to take into account the coefficient $\mu=0.0614^{\circ} \mathrm{C} \cdot \mu \mathrm{m}^{-1}$ and the initial clearance of $37.5 \mu \mathrm{m}$. In equation (3), the increment is $2.3^{\circ} \mathrm{C}$, so the average diagnostic temperature is $26.0^{\circ} \mathrm{C}$, which is $8.85 \%$ less than the average diagnostic temperature in the $28.5^{\circ} \mathrm{C}$ test. Similar approach is applied in studies of the technical condition of bearings of disk harrows by their thermal radiation, where similar accuracy of results is noted [11].

The implementation of the developed algorithm is considered as a thermography process on the example of a mechanical unit [12].

The technology is useful when adapting to thermometric diagnostics of various units of mechanical transmissions of equipment in operation. The most rational application of the technology is at the stage of design of transmission assemblies due to the application of 3D-modeling and simulation of the finite element method, as well as in the design of built-in control and diagnostic systems.

\section{Conclusions}

1. The analytical mathematical model of temperature estimation in the friction zone of the joint CBA is refined, which takes into account the influence of structural, technological and operational factors on their temperature regime.

2. On the basis of the simulation technique by means of the finite-element analysis of temperature fields the relation between temperature in the friction zone and the diagnostic temperature through the proportionality coefficient $k=0.202$ is established.

3. Based on the results of the bench tests, the influence of the initial radial play of the CBA of the joint on the temperature through the proportionality coefficient $\mu=0.0614^{\circ} \mathrm{C} \cdot \mu \mathrm{m}^{-1}$ was taken into account, which allowed to verify the refined mathematical model of temperature in the friction zone.

4. Based on the generalization of the above results, an algorithm for the application of thermometric nondestructive testing has been developed on the example of drive line joints. The algorithm is promising for adaptation to diagnostics of various units of mechanical transmissions.

\section{References}

[1] Ерохин М.Н. Взаимосвязь точности и надежности соединений при ремонте сельскохозяйственной техники (The relationship between the accuracy and reliability of connections in the repair of agricultural machinery). Vestnik FGOU VPO MGAU, 2016. No 2. pp. 22-25. (In Russian).

[2] Erokhin M.N., Leonov O.A., Kataev Yu.V., Mel'nikov O.M. Tightness and leakage in applying reinforced rubber sleeves to shafts. Russian Engineering Research, 2019, vol. 39, No 6, pp. 459-462.

[3] Leonov O.A., Shkaruba N.Zh., Vergazova Yu.G. Determining the tolerances in fitting for joints with interference. Russian Engineering Research, 2019, vol. 39, No 7, pp. 544-547.

[4] Eresko S.P., Eresko T.T., Kukushkin E.V., Menovshchikov V.A. Influence of vibrational loads on needle skew in cardan-joint bearings. Russian Engineering Research, 2018, vol. 38, No 9, pp. 651-655.

[5] Kukushkin E.V., Kukushkin S.V., Menovshchikov V.A., Semenukha O.V. Construction of joint with separator. Journal of Advanced Research in Technical Science, 2017, No 7-1, pp. 33-36.

[6] Makhovskaya Y.Y. Modeling of stationary frictional heating of a coated body. Journal of friction and wear, 2019, vol. 40, No 3, pp. 258-265.

[7] Malekan A., Rouhani S. Model of contact friction based on extreme value statistics. Friction, 2019, vol. 7, No 4, pp. 327-339.

[8] Izmailov V.V., Novoselova M.V. On the temperature effect on the parameters of the specific friction force of metals. Journal of friction and wear, 2018, vol. 39, No 4, pp. 289-293.

[9] Pastukhov A.G., Timashov E.P., Parnikova T.V. System approach to assessment of thermal stress of units of transmissions. Applied Engineering Letters, 2017, vol. 2, No 2, pp. 65-68.

[10] Pastukhov A.G., Timashov E.P., Parnikova T.V. Monitoring of reliability of agricultural machinery on the basis of methods of thermodiagnostics of drive lines. Traktori i pogonske mašhine, 2017, vol. 22, No 1-2, pp. 31-38. 
[11]Ильин П.А. Моделирование технического состояния подшипников дисковых борон по тепловому излучению (Simulation of technical condition of disk harrows bearings by thermal radiation). Izvestiya Sankt-Peterburgskogo gosudarstvennogo agrarnogo universiteta, 2016, No 42, pp. 340-346 (In Russian).

[12]ГОСТ Р ИСО 18434-1-2013 Контроль состояния и диагностика машин. Термография. Часть 1. Общие методы (ISO 18434-1:2008 Condition monitoring and diagnostics of machines Thermography - Part 1: General procedures). M. Standartinform, 2014, 25 p. (In Russian). 